\title{
Minimally Invasive Spine Surgery versus Open Posterior Instrumentation Surgery for Unstable Thoracolumbar Burst Fracture
}

\author{
Sung-Ha Hong, Seung-Pyo Suh, Jiung Yeom, Joo-Young Kim, Seung Gi Lee, Jeong-Woon Han \\ Department of Orthopedic Surgery, Sung-Ae Hospital, Seoul, Korea
}

\section{Study Design: Retrospective study.}

Purpose: To compare the clinical and radiological results of minimally invasive spine surgery (MISS) and open posterior instrumentation surgery for the treatment of unstable burst fractures.

Overview of Literature: MISS has exhibited postoperative outcomes similar to those obtained using open posterior instrumentation in various spine diseases. There remains no consensus regarding the use of MISS in the treatment of unstable burst fracture.

Methods: We enrolled 40 patients who underwent either MISS (M group, 20 patients) or open posterior instrumentation surgery (0 group, 20 patients) for the treatment of traumatic unstable burst fractures. Clinical outcomes were evaluated based on postoperative back pain, operation time, blood loss, hospital stay duration, and perioperative complications. For radiologic evaluation, preoperative magnetic resonance imaging and plain radiography were performed before and after the surgery to evaluate the changes in the kyphotic angle and fracture union.

Results: The change in the kyphotic angle was $-8.2^{\circ} \pm 5.8^{\circ}$ in the $\mathrm{M}$ group and $-8.0^{\circ} \pm 7.8^{\circ}$ in the 0 group. No significant difference was noted in terms of the change in the kyphotic angle ( $p=0.94, t$-test) after 12 months of surgery. The Visual Analog Scale score was $1.5 \pm 0.7$ points in the $M$ group, while it was $5.2 \pm 1.4$ points in the 0 group. In the $M$ group, back pain has significantly decreased $(p<0.01$, $t$-test). The estimated blood loss was $195.5 \mathrm{~mL}$ in the $\mathrm{M}$ group and $1,077.5 \mathrm{~mL}$ in the 0 group; the operation time was significantly decreased in the 0 group from 290.7 to 120.7 minutes in the $M$ group ( $p<0.05, t$-test) ( $p=0.36, t$-test). The average duration of hospital stay was 36.0 days in the $M$ group and 41.9 days in the 0 group $(p=0.36, t$-test).

Conclusions: For the treatment of unstable burst fractures, MISS showed significant differences in terms of postoperative back pain, operation time, and blood loss as compared to open posterior instrumentation surgery.

Keywords: Spine; Spinal fractures; Minimally invasive surgical procedures; Instrumentation; Pedicle screws

\section{Introduction}

Thoracolumbar fracture is identified as the most common form of vertebral fracture, with an incidence of 18 to 30 per 100,000 people every year [1,2]. Burst fracture induces damage to the anterior and middle column of the vertebral body by vertical compression force and causes retropulsion of the middle column. The stability of the

Received Feb 9, 2021; Revised Feb 9, 2021; Accepted Mar 8, 2021

Corresponding author: Seung-Pyo Suh

Department of Orthopedic Surgery, Sung-Ae Hospital, 22, Yeouidaebang-ro 53-gil, Yeongdeungpo-gu, Seoul 07354, Korea

Tel: +82-2-840-7235, Fax: +82-2-840-7435, E-mail: arcseo@hanmail.net 
vertebral body in burst fractures is a crucial factor that influences the choice of treatment. Unstable burst fracture requires surgical treatment because of post-traumatic kyphosis, neurologic deficit, and persistent radiating pain. Open posterior instrumentation technique can induce iatrogenic permanent muscle deformity and persistent postoperative pain owing to damage to the paraspinal muscle and surrounding soft tissue because of excessive traction during surgery [3]. Minimally invasive spinal surgery has been widely used as an effective alternative to conventional posterior instrumentation.

Previous studies have shown that minimally invasive spinal surgery showed similar postoperative outcomes with less soft tissue damages and fewer surgery-related iatrogenic injuries than open posterior instrumentation [3-7]. In addition, minimally invasive spinal surgery can be performed with less postoperative pain and blood loss due to less soft tissue dissection, leading to faster recovery after surgery compared to open posterior instrumentation. However, there were no previous reports comparing the clinical and radiological outcomes of minimally inva- sive spinal surgery and open posterior instrumentation for the treatment of unstable burst fractures. Thus, in this study, we aimed to assess and compare the postoperative clinical and radiologic outcomes of minimally invasive spinal surgery and open posterior instrumentation for the treatment of unstable burst fractures.

\section{Materials and Methods}

\section{Study design}

The study protocol was approved by the Institutional Review Board of Sung-Ae Hospital (IRB approval no., SA2020-05). Informed consent was obtained from all the study subjects. We then investigated 42 patients who underwent spinal fusion surgeries for traumatic unstable burst fracture from April 2014 to December 2018 (Fig. 1A). The exclusion criteria were as follows: diagnosis of osteoporosis, spinal tumor, and non-traumatic fracture. Two patients were excluded as per the exclusion criteria, and 40 patients were then enrolled. Twenty patients un-
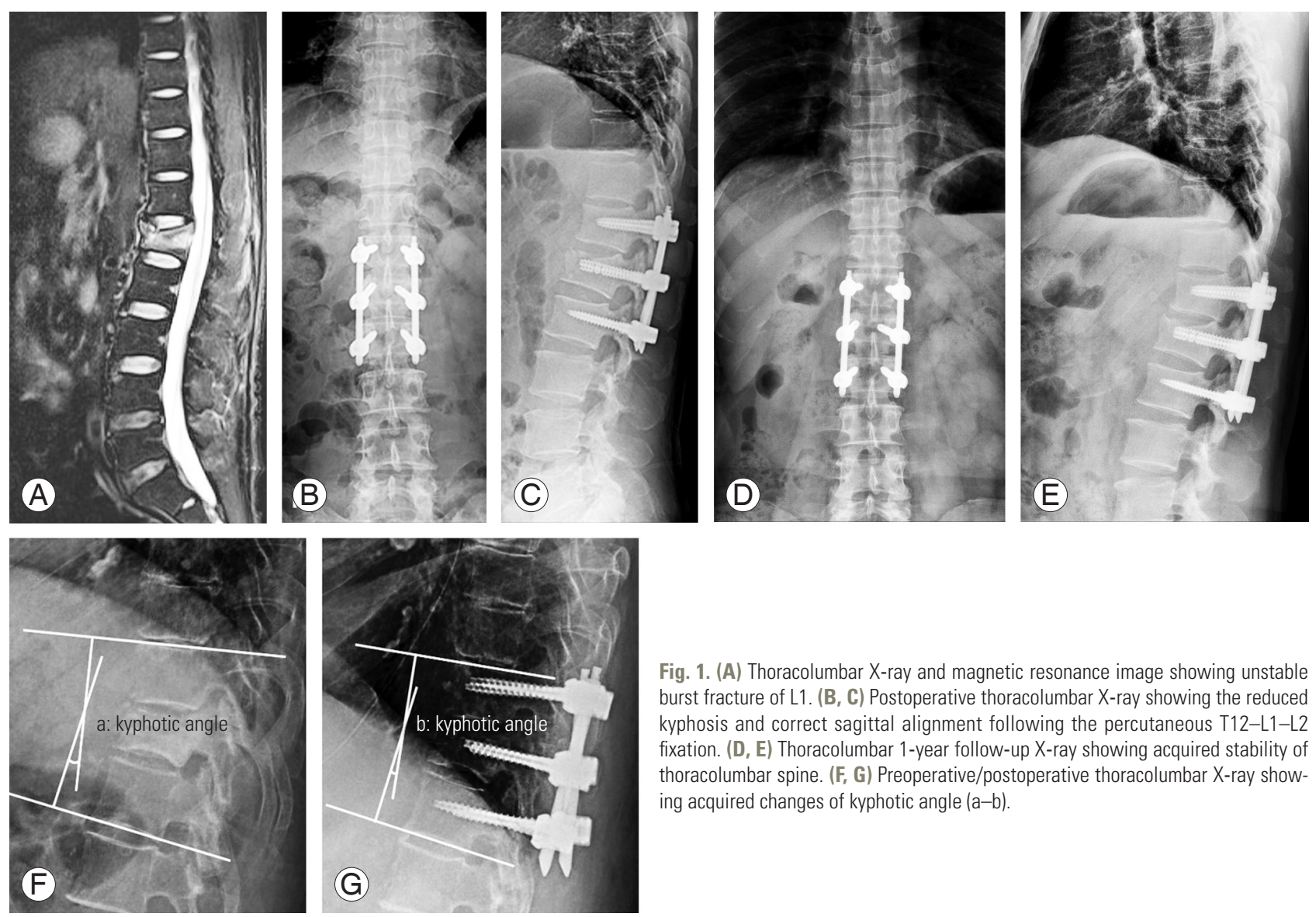

Fig. 1. (A) Thoracolumbar $X$-ray and magnetic resonance image showing unstable burst fracture of $\mathrm{L}$ 1. (B, C) Postoperative thoracolumbar $\mathrm{X}$-ray showing the reduced kyphosis and correct sagittal alignment following the percutaneous T12-L1-L2 fixation. (D, E) Thoracolumbar 1-year follow-up X-ray showing acquired stability of thoracolumbar spine. (F, G) Preoperative/postoperative thoracolumbar X-ray showing acquired changes of kyphotic angle $(\mathrm{a}-\mathrm{b})$. 
derwent minimally invasive posterior instrumentation (M group) (Fig. 1B-G), whereas the other 20 patients underwent open posterior instrumentation (O group) (Fig. 2). Clinical outcomes and radiographic outcomes were assessed. Clinical outcomes included Visual Analog Scale (VAS) score, operation time, blood loss volume, hospital stay duration, and complications. The VAS was administered at 3 days after the surgery to assess postoperative back pain. Data on operation time and blood loss volume were retrieved from the anesthesia record sheets. Operation time was measured as per the total time taken from skin incision to wound closure. Length of hospital stay and patient discharge were when the patients were able to ambulate at least for 30 minutes and wanted to be discharged.

Radiologic outcomes included changes in the kyphotic angle and radiologic fracture union. Series of simple radiographs, including anterior-posterior, lateral, flexion at standing, and extension at standing views of the thoracolumbar spine were taken preoperatively, immediately postoperatively, and 1 year postoperatively. Changes in the kyphotic angle were measured from the thoracolumbar spine lateral view using the kyphotic angle calculation method. IBM SPSS ver.23.0 for Windows (IBM Corp., Armonk, NY, USA) was used for all the statistical analyses including $t$-test and chi-square test. The statistical significance was set as $p$-value $<0.05$.

\section{Surgical technique}

1) Minimally invasive spinal surgery technique

Pedicle screws were placed at the fracture site, one level above and one level below the level of injury. Pedicle screw size varied from 5.5 to $6.5 \mathrm{~mm}$, while the screw length varied from 40 to $45 \mathrm{~mm}$, based on the size of the vertebral body measured on preoperative computed tomography image. Fluoroscopy was used to visualize and mark the appropriate pedicles. Postural reduction was performed in the prone position. Paramedian incisions were made at the pedicle sites, and a vertebroplasty needle was placed into the vertebral body under fluoroscopy. A guide pin was inserted, and a vertebroplasty needle was removed. Serial dilators were inserted, and pedicle screws were inserted. Additional reduction was performed with the joystick maneuver with minimally invasive spinal surgery instruments. Rods were used to connect the pedicle screws. Screw caps were then inserted, and antirotation instruments were used to fixate the rods.

\section{2) Open posterior instrumentation}

Pedicle screws were placed at the fracture site, one level above and one level below the level of injury. Pedicle screw size varied from 5.5 to $6.5 \mathrm{~mm}$, whereas the screw length varied from 40 to $45 \mathrm{~mm}$, based on the size of the vertebral body measured using preoperative computed tomography image. Fluoroscopy was used to visualize and
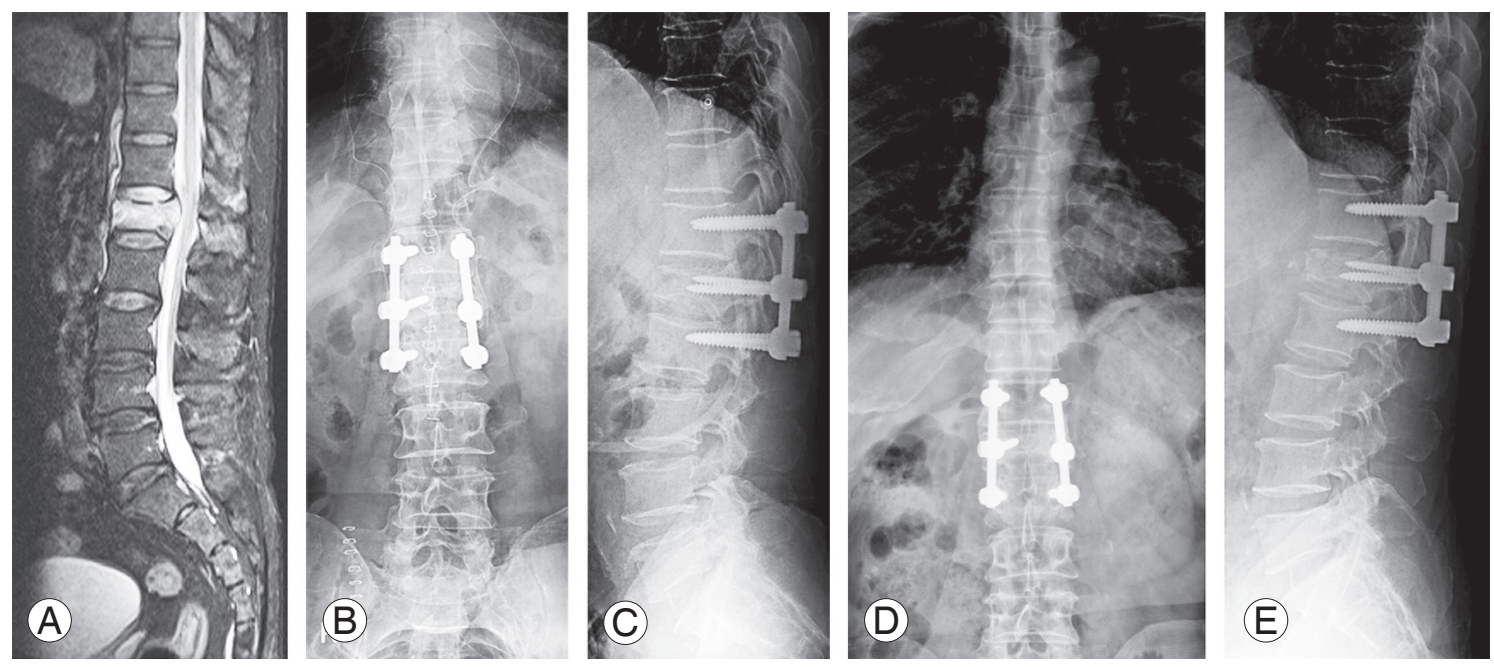

Fig. 2. (A) Thoracolumbar X-ray and magnetic resonance image showing a unstable burst fracture of L1. (B, C) Postoperative thoracolumbar X-ray showing the reduced kyphosis and correct sagittal alignment following the open surgery T12-L1-L2 fixation. (D, E) Thoracolumbar 1-year followup X-ray showing acquired stability of the thoracolumbar spine. 
mark the fracture site. Postural reduction was performed in the prone position. A midline posterior longitudinal incision was made, the fascia was cut, the spinal muscle was retracted, and the transverse processes were exposed. Pedicle screws were then inserted using the intersection technique. The rods were inserted and fixated.

\section{Results}

\section{Patient demographics}

The experiment group included 20 patients who had undergone minimally invasive posterior instrumentation (M group: 10 men and 10 women; mean age, $54.6 \pm 14.2$ years). The control group included 20 patients who had undergone open posterior instrumentation ( $\mathrm{O}$ group: 14 men and seven women; mean age, $63.0 \pm 13.1$ years). No significant difference was observed for basic patient demographics ( $p=0.33, \chi^{2}$ test) (Table 1$)$ and distribution of fracture levels ( $p=0.47, \chi^{2}$ test) (Table 1$)$. In the M group, the fracture distributions were T11 (one patient, 5.0\%), T12 (three patients, 15.0\%), L1 (eight patients, $40.0 \%$ ), and L2 (five patients, 25.0\%), and L3 (three patients, 15.0\%). Meanwhile, in the O group, the fracture distributions were T11 (two patients, 10.0\%), T12 (four patients, 20.0\%), L1 (eight patients, 40.0\%), and L2 (six patients, $30.0 \%)$. Injury of the posterior ligament complex showed no significant difference $\left(p=0.21, \chi^{2}\right.$ test) (Table 1$)$. Fifteen patients in the $\mathrm{M}$ group (75.0\%) and 18 in the O group $(90.0 \%)$. Mean numbers of fused spinal segments were $2.5 \pm 0.6$ in the $\mathrm{M}$ group and $2.7 \pm 1.4$ in the $\mathrm{O}$ group.

\section{Clinical outcomes}

Mean VAS scores measured at 3 days postoperatively showed a significant difference (M group, 1.5 \pm 0.7 ; O group, $5.2 \pm 1.4 ; p=0.00, t$-test) (Table 2 ). The average volume of blood loss showed a significant difference $(\mathrm{M}$ group, $195.5 \pm 310.8 \mathrm{~mL}$; O group, $1,077.5 \pm 877.0 \mathrm{~mL}$; $p=0.000, t$-test) (Table 2). Operation time showed a significant difference (M group, 120.8 \pm 18.7 minutes; O group, $290.8 \pm 74.6$ minutes; $p=0.00, t$-test) (Table 2 ). The average length of hospital stay showed no significant difference (M group, 41.9 \pm 14.9 ; O group, 36.0 $\pm 24.4 ; p=0.36, t$-test) (Table 2). With respect to postoperative complications, one patient in the M group had wound dehiscence. In the O group, the following postoperative complications were
Table 1. Demographic data for the minimally invasive spine surgery group versus open posterior instrumentation group

\begin{tabular}{lccc} 
Characteristic & M group & O group & $p$-value $\left(\chi^{2}\right)$ \\
Age (yr) & $54.6 \pm 14.2$ & $63.0 \pm 13.1$ & 0.06 \\
Sex & & & 0.33 \\
$\quad$ Male & 14 & 10 & \\
$\quad$ Female & 6 & 10 & \\
\hline No. of instrumented segments & $2.5 \pm 0.6$ & $2.7 \pm 1.4$ & 0.78 \\
\hline Posterior ligament complex injury & & & 0.21 \\
\hline Present & 15 & 18 & \\
\hline Absent & 5 & 2 & \\
\hline Fracture level & & & \\
\hline T11 & 1 & 2 & \\
\hline T12 & 3 & 4 & \\
\hline L1 & 8 & 8 & 0.46 \\
\hline L2 & 5 & 6 & $(3.4)$ \\
\hline L3 & 3 & 0 & \\
\hline
\end{tabular}

Values are presented as mean \pm standard deviation or number. $\mathrm{M}$ group: minimally invasive spinal surgery group; 0 group: open posterior instrumentation group. A $p$-value $<0.05$ is statistically significant.

Table 2. Back pain (VAS), operation time, blood loss, and hospital stay in patients with minimally invasive spine surgery group versus open surgery group

\begin{tabular}{lccl} 
Variable & M group & 0 group & $p$-value \\
\hline VAS score & $1.5 \pm 0.7$ & $5.2 \pm 1.4$ & $0.000^{* *}$ \\
Operation time (min) & $120.8 \pm 18.7$ & $290.8 \pm 74.6$ & $0.000^{* *}$ \\
\hline Blood loss (mL) & $195.5 \pm 310.8$ & $1,077.5 \pm 577.0$ & $0.000^{* *}$ \\
Hospital stays (day) & $41.9 \pm 14.9$ & $36.0 \pm 24.4$ & 0.36 \\
\hline
\end{tabular}

Values are presented as mean \pm standard deviation. M group: minimally invasive spinal surgery group; 0 group: open posterior instrumentation group. VAS, Visual Analog Scale. ${ }^{* *} p<0.01$

detected: cardiovascular accident $(\mathrm{n}=1)$, aspiration pneumonia $(\mathrm{n}=1)$, and acute respiratory distress syndrome $(n=1)$. No reoperation was performed in either group.

\section{Radiologic outcomes}

Changes in the kyphotic angle after surgery showed no significant difference (M group, $8.0^{\circ} \pm 7.8^{\circ}$; O group, $8.2^{\circ} \pm 5.8^{\circ} ; p=0.94, t$-test $)$. All the patients in both groups showed fracture union after surgery; thus, statistical analysis was not performed. 


\section{Discussion}

Approximately two-thirds of traumatic vertebral fractures involve the thoracolumbar junction, and about half of traumatic vertebral fractures were unstable burst fractures. The L1 vertebral body was most commonly affected, followed by the T12 vertebral body as the second most commonly affected [8]. Traumatic burst fractures of the thoracolumbar spine showed an initial kyphotic angle of $10^{\circ}-32^{\circ}$ by anterior pillar injuries $[9,10]$. Anatomically, unstable burst fractures of the thoracolumbar junction often required correction of the kyphotic angle and spinal canal decompression. Willen et al. [11] suggested that the burst fractures were unstable when anterior vertebral compression rates were $>50 \%$, spinal canal compromises were $>50 \%$, rotational malalignments were present at the fracture site, and the L1 body was affected. The indications of minimally invasive spinal surgery are increasing, owing to the development of new instruments and improvements in surgical techniques. The current indications include traumatic thoracolumbar fractures, degenerative spondylolisthesis, and herniated lumbar disc. Minimally invasive spinal surgery offers the advantages of reduced operation time and surrounding soft tissue damage; however, there is limited clinical evidence that supports the effectiveness and safety of minimally invasive surgery as compared to those of conventional open posterior instrumentation. In this study, minimally invasive spinal surgery showed reduced operation time, blood loss, and postoperative back pain as compared to conventional open posterior instrumentation. The rate of postoperative complications was low, and the radiologic outcomes showed no significant difference between the two groups. Open posterior instrumentation, compared to other types of arthrodesis, has disadvantages, including posterior migration of the bone graft, nerve root, and muscle injury caused by excessive traction, extradural fibrosis, chronic nerve root inflammation, dural injuries, and iatrogenic injuries of the anterior and posterior column [12]. According to Myeroff and Archdeacon [13], 37.9\% patients reported donor site pain for 3 months, and 18.4\% patients had persistent donor site pain for 2 years when open posterior instrumentation and autogenous iliac bone graft were performed simultaneously. Loss of the midline of supraspinous ligament-interspinous ligament complex caused reduced flexion power and delayed vertebral instabilities [14]. Blood loss because of extensive soft tissue dissection and muscle splitting during surgery caused increased postoperative back pain and rate of postoperative complications [15,16]. Extensive soft tissue dissection and degeneration of paraspinal muscle increased the rate of post spinal surgery syndrome because of increased risks of nerve injury and muscle atrophy $[17,18]$. Styf and Willen [19] reported that the traction device used to expose the posterior column could induce focal ischemia of the paraspinal muscles. Furthermore, Kahanovitz et al. [20] reported that open discectomy performed for young patients induced reduction of lumbar flexion power by $30 \%$. Mayer et al. [21] reported that 15\%-20\% patients showed evidences of paraspinal muscle atrophy on computed tomography images when the extensive open posterior approach was used. Lanzino et al. [22] reported that $16 \%$ of the patients showed worsened clinical outcomes after open posterior instrumentation. Minimally invasive spinal surgery reduced iatrogenic soft tissue injury by splitting between multifidus and longissimus and could thus offer advantages over open posterior instrumentation. In a biomechanical study, early segmental internal fixation could improve axial compression, torque, and strength of fixated vertebra when flexion-extension torque load [23]. As per one report, pedicle screw fixation in posterior instrumentation improved early ambulation, pseudoarthrosis, and rate of recipient site posterior migration [24]. With minimally invasive spinal surgery technique, pedicle screw fixation could be performed percutaneously without significant infection, blood loss, multiple muscle atrophy, muscle injury, and elongated operation time $[25,26]$. Foley et al. [7], Park et al. [27], and Min et al. [28] reported lower blood loss with minimally invasive spinal surgery compared to that with conventional open posterior instrumentation. Studies have reported on reduced intraoperative blood loss, hospital stay duration, and muscle atrophy after minimally invasive spinal surgery for the treatment of lumbar spine diseases [29,30]. Cho et al. [31] suggested that increased blood loss during surgery led to increased incidence of early postoperative complications. With small incisions and less traction compared to those with the conventional open method, minimally invasive technique could be a surgical treatment option for hematologically and immunologically compromised patients. Khoo et al. [3] reported that patients who underwent minimally invasive posterior instrumentation had a shorter duration of hospital stay, with an average hospital stay of 2.8 days and less frequent use of intravenous pain medication than 
that in patients who underwent open posterior instrumentation, with an average hospital stay of 5-7 days. In this study, the duration of hospital stay showed no significant difference. The patients in this study were discharged when they wanted to be discharged; their hospital stay duration was determined as per their insurance coverage. Patients with industrial and traffic accidents tended to be hospitalized for longer periods of time. Deyo et al. [32] reported that increased operation time led to increased rate of postoperative complications in spinal surgeries. Foley et al. [7] reported that minimally invasive technique had an average operation time of 240 minutes because it involved a smaller window for operation, challenges in determining the anatomical landmarks, and longer learning curve than that in conventional open posterior instrumentation. Park et al. [27] have also reported that minimally invasive spinal surgery had a longer operation time than that with open posterior instrumentation and lower postoperative VAS scores than those with open posterior instrumentation. In this study, $M$ group had average operation time of 120 minutes; this was significantly shorter than that of the $\mathrm{O}$ group. This result might be attributable to the development of instruments and difference in the operator's learning curve. Park et al. [27] suggested that the minimally invasive technique had sufficient nerve decompression and expansion of the intervertebral disc to achieve successful union of the vertebral bodies. Similar to that in previous studies, our result showed no significant differences in terms of the changes in the kyphotic angle and fracture union rate. The limitations of this study were the relatively smaller sample size in the minimally invasive spinal surgery group, its retrospective study design, and unmatched number of fixated segments between the two groups. The $\mathrm{M}$ group had a smaller average number of fixated segments than the $\mathrm{O}$ group; thus, the operation time, blood loss, postoperative back pain, and complication rate might have been affected. Moreover, differences in the insurance coverage were not controlled; thus, the hospital stay duration involved a bias because of different secondary gains of different patients' situations. Thus, future research should include a larger sample size and a longer follow-up period to overcome the limitations of this present study to observe more objective comparisons between the minimally invasive technique and open posterior instrumentation. Despite these limitations, this study was the first study to compare the clinical and radiological outcomes of minimally invasive spinal surgery and open posterior instrumentation for the treatment of unstable burst fractures.

\section{Conclusions}

Clinical and radiological outcomes were examined and compared between patients who underwent minimally invasive spinal surgery and those who underwent open posterior instrumentation for the treatment of unstable burst fractures. As per our findings, it was determined that the minimally invasive spinal surgery group had less blood loss during surgery, shorter operation time, and less postoperative pain. The two groups showed no significant differences in terms of hospital stay duration, kyphotic angle changes, fracture union rate, and postoperative complication rate. Reoperation or instrument failure was not observed in the groups. The surgical outcomes of minimally invasive posterior instrumentation were similar to those of open posterior instrumentation; the minimally invasive technique offered faster recovery and rehabilitation than open posterior instrumentation.

\section{Conflict of Interest}

No potential conflict of interest relevant to this article was reported.

\section{ORCID}

Sung-Ha Hong: https://orcid.org/0000-0002-2913-0381; Seung-Pyo Suh: https://orcid.org/0000-0002-1457-8984; Jiung Yeom: https://orcid.org/0000-0003-2359-8896; JooYoung Kim: https://orcid.org/0000-0002-8997-1406; Seung Gi Lee: https://orcid.org/0000-0003-0432-6254; Jeong-Woon Han: https://orcid.org/0000-0003-1121-2810

\section{Author Contributions}

Sung-Ha Hong: developed theory and supervised the project; Seung-Pyo Suh: designed model; Jiung Yeom: discussed the results and contributed to the final manuscript; Joo-Young Kim: designed model and analyzed data; Seung Gi Lee: analyzed data, wrote the manuscript, and revised the manuscript; and Jeong-Woon Han: analyzed data. 


\section{References}

1. Hu R, Mustard CA, Burns C. Epidemiology of incident spinal fracture in a complete population. Spine (Phila Pa 1976) 1996;21:492-9.

2. Jansson KA, Blomqvist P, Svedmark P, et al. Thoracolumbar vertebral fractures in Sweden: an analysis of 13,496 patients admitted to hospital. Eur J Epidemiol 2010;25:431-7.

3. Khoo LT, Palmer S, Laich DT, Fessler RG. Minimally invasive percutaneous posterior lumbar interbody fusion. Neurosurgery 2002;51(5 Suppl):S166-81.

4. Guiot BH, Khoo LT, Fessler RG. A minimally invasive technique for decompression of the lumbar spine. Spine (Phila Pa 1976) 2002;27:432-8.

5. Foley KT, Gupta SK. Percutaneous pedicle screw fixation of the lumbar spine: preliminary clinical results. J Neurosurg 2002;97(1 Suppl):7-12.

6. Foley KT, Lefkowitz MA. Advances in minimally invasive spine surgery. Clin Neurosurg 2002;49:499517.

7. Foley KT, Holly LT, Schwender JD. Minimally invasive lumbar fusion. Spine (Phila Pa 1976) 2003;28(15 Suppl):S26-35.

8. Mathews HH Long BH. Endoscopy assisted percutaneous anterior interbody fusion with subcutaneous suprafascial internal fixation: evolution of technique and surgical considerations. Orthopaedics 1995;3:496-500.

9. Alanay A, Yazici M, Acaroglu E, Turhan E, Cila A, Surat A. Course of nonsurgical management of burst fractures with intact posterior ligamentous complex: an MRI study. Spine (Phila Pa 1976) 2004;29:242531.

10. Carl AL, Tranmer BI, Sachs BL. Anterolateral dynamized instrumentation and fusion for unstable thoracolumbar and lumbar burst fractures. Spine (Phila Pa 1976) 1997;22:686-90.

11. Willen J, Anderson J, Toomoka K, Singer K. The natural history of burst fractures at the thoracolumbar junction. J Spinal Disord 1990;3:39-46.

12. Lowery GL, Kulkarni SS. Posterior percutaneous spine instrumentation. Eur Spine J 2000;9(Suppl 1):S126-30.

13. Myeroff C, Archdeacon M. Autogenous bone graft: donor sites and techniques. J Bone Joint Surg Am 2011;93:2227-36.
14. Tsai RY, Yang RS, Bray RS Jr. Microscopic laminotomies for degenerative lumbar spinal stenosis. J Spinal Disord 1998;11:389-94.

15. Jackson RK. The long-term effects of wide laminectomy for lumbar disc excision: a review of 130 patients. J Bone Joint Surg Br 1971;53:609-16.

16. Rantanen J, Hurme M, Falck B, et al. The lumbar multifidus muscle five years after surgery for a lumbar intervertebral disc herniation. Spine (Phila Pa 1976) 1993;18:568-74.

17. See DH, Kraft GH. Electromyography in paraspinal muscles following surgery for root compression. Arch Phys Med Rehabil 1975;56:80-3.

18. Sihvonen T, Herno A, Paljarvi L, Airaksinen O, Partanen J, Tapaninaho A. Local denervation atrophy of paraspinal muscles in postoperative failed back syndrome. Spine (Phila Pa 1976) 1993;18:575-81.

19. Styf JR, Willen J. The effects of external compression by three different retractors on pressure in the erector spine muscles during and after posterior lumbar spine surgery in humans. Spine (Phila Pa 1976) 1998;23:354-8.

20. Kahanovitz N, Viola K, Gallagher M. Long-term strength assessment of postoperative diskectomy patients. Spine (Phila Pa 1976) 1989;14:402-3.

21. Mayer TG, Vanharanta H, Gatchel RJ, et al. Comparison of CT scan muscle measurements and isokinetic trunk strength in postoperative patients. Spine (Phila Pa 1976) 1989;14:33-6.

22. Lanzino G, Shaffrey CI, Ray CD. Posterior lumbar interbody fusion. In: Benzel EC, editor. Spine surgery: techniques, complication avoidance, and management. New York (NY): Churchill Livingstone; 1999. p. 311-31.

23. Branch CL Jr. Posterior lumbar interbody fusion. In: Hardy RW Jr, editor. Lumbar disc disease. 2nd ed. New York (NY): Raven Press; 1993. p. 187-200.

24. Matsuzaki H, Tokuhashi Y, Matsumoto F, Hoshino M, Kiuchi T, Toriyama S. Problems and solutions of pedicle screw plate fixation of lumbar spine. Spine (Phila Pa 1976) 1990;15:1159-65.

25. Sidhu KS, Herkowitz HN. Spinal instrumentation in the management of degenerative disorders of the lumbar spine. Clin Orthop Relat Res 1997;(335):3953.

26. Foley KT, Gupta SK, Justis JR, Sherman MC. Percutaneous pedicle screw fixation of the lumbar spine. 
Neurosurg Focus 2001;10:E10.

27. Park Y, Ha JW, Sung SY, Oh HC, Yoo JH, Lee YT. Minimally invasive posterior lumbar interbody fusion: comparison with traditional open surgery. J Korean Orthop Assoc 2006;41:288-96.

28. Min SH, Yoo JS, Yoon SH, Rhee CW. Perioperative safety and efficacy of multilevel minimally invasive transforaminal lumbar interbody fusion: comparison with conventional open surgery. J Korean Orthop Assoc 2012;47:416-24.

29. Khan NR, Clark AJ, Lee SL, Venable GT, Rossi NB, Foley KT. Surgical outcomes for minimally invasive vs open transforaminal lumbar interbody fusion: an updated systematic review and meta-analysis. Neurosurgery 2015;77:847-74.
30. Goldstein CL, Macwan K, Sundararajan K, Rampersaud YR. Comparative outcomes of minimally invasive surgery for posterior lumbar fusion: a systematic review. Clin Orthop Relat Res 2014;472:1727-37.

31. Cho KJ, Suk SI, Park SR, et al. Complications in posterior fusion and instrumentation for degenerative lumbar scoliosis. Spine (Phila Pa 1976) 2007;32:22327.

32. Deyo RA, Ciol MA, Cherkin DC, Loeser JD, Bigos SJ. Lumbar spinal fusion: a cohort study of complications, reoperations, and resource use in the Medicare population. Spine (Phila Pa 1976) 1993;18:1463-70. 